\title{
Editorial
}

\section{New Senior Editor Announcement}

The editorial team of Maternal and Child Nutrition are delighted to announce the appointment of Professor Rafael Pérez-Escamilla of the Yale School of Public Health as Senior Editor from January 2016. Rafael will succeed Professor Kay Dewey who has contributed greatly to the growth and success of the journal over the last 5 years. Since her appointment in 2010, Kay has helped position the journal as the leading place for publication of research directed at the translation of scientific findings into programmatic and policy initiatives to improve maternal and child nutrition worldwide. This has included overseeing the publication of important Supplement issues of Maternal and Child Nutrition that have brought together operational and 'delivery science' research examining critical questions of how to implement culturally acceptable, cost-effective and sustainable programmes that will lead to lasting improvements. On the behalf of the Editorial Board, we would like to thank her for her invaluable input and look forward to her continued support of the journal in the coming years.

Rafael Pérez-Escamilla, $\mathrm{PhD}$, is a renowned Professor of Epidemiology and Public Health and Director of the Global Health Concentration and of the Office of Public Health Practice at the Yale School of Public Health. His maternal-child public health nutrition research has led to improvements in breastfeeding protection, promotion and support worldwide through health facility and community-based initiatives, including breastfeeding peer counselling. He has also made major contributions to the development, implementation and evaluation of maternal, infant and young child community nutrition programmes globally. His research group has also played a key role advancing household food security measurement globally, a contribution that has already led to a much better understanding of the risk factors for and consequences of household food security in low and middle-income countries. His $\$ 20 \mathrm{~m}$ research programme has been funded by the National Institutes of Health (NIH), the United States Department of Agriculture (USDA), the Centers for Disease Control and Prevention (CDC), the Family Larsson-Rosenquist Foundation, the Bill \& Melinda Gates Foundation and the Ethel Donaghue Foundation.

He has published over 155 research articles and has edited numerous thematic issues/sections in prestigious journals. He has served as a principal mentor to over 60 graduate students and dozens of visiting scholars from all over the world. He is a member of the Institute of Medicine Food and Nutrition Board. He served in both the 2010 and 2015 USA Dietary Guidelines Advisory Committees and is currently serving in the USDA/DHHS B-24/P Dietary Guidelines Technical Expert Consultation group. He has served as an expert advisor to the World Health Organization-Geneva nutrition guidelines committee and the Food and Agriculture Organization Voices of the Hungry project. $\mathrm{He}$ is a member of the steering committee of the 2016 Early Child Development Lancet Series. He is the current President of the International Society for Research in Human Milk and Lactation and has been senior scientific advisor to maternal-child nutrition and food security projects funded by the United States Agency for International Development (USAID), the United States Department of Agriculture (USDA), the National Institutes of Health, the World Bank and numerous United Nations agencies including the Food and Agriculture Organization (FAO), UNICEF, the World Health Organization and the Pan American Health Organization (PAHO). He has served in the editorial boards of the Journal of Nutrition, the Journal of Human Lactation, the Journal of Hunger and Environmental Nutrition and Global Food Security. He lectures globally and has received numerous prestigious academic, community outreach and research awards including the 2015 Journal of Human Lactation Patricia Martens Annual Award for Excellence in Breastfeeding Research. He obtained BS in Chemical Engineering at the Universidad Iberoamericana in Mexico City, and his Masters in Food Science and his $\mathrm{PhD}$ in Nutrition at the University of California at Davis. 
Rafael will work closely with Dr Victoria Hall Moran to build on the excellent reputation of the journal as a forum for dissemination of the latest research and innovation in all aspects of practice and policy that impact on nutrition and its outcomes in women and their children, both in early and later life. Keeping with the spirit of the 2015 Sustainable Development Goals in the context of a globalized world,
Rafael and Victoria strongly encourage the submission of high quality interdisciplinary maternal-child nutrition research with strong policy implications for low, middle as well as high-income countries.

Victoria Hall Moran Rafael Pérez-Escamilla Senior Editors 